\title{
Primary Endoscopic Stapes Surgery: A Comparison of Adipose Tissue and Gelfoam Seal
}

\author{
Pradeep Pradhan $^{1}$ (D) Anindya Nayak ${ }^{1} \cdot$ Sidharth Pradhan $^{1} \cdot$ Prity Sharma $^{1} \cdot$ \\ Chappity Preetam ${ }^{1} \cdot$ Pradipta Kumar Parida ${ }^{1}$
}

Received: 3 August 2020/ Accepted: 5 October 2020/Published online: 23 October 2020

(C) The Author(s) 2020

\begin{abstract}
To compare the efficacy between the commonly used sealing materials, i.e., adipose tissue and the gelfoam in primary endoscopic stapedotomy. Lobular fat and gelfoam have been used in patients who underwent endoscopic stapedotomy between two groups, each containing 29 patients. The hearing outcomes and postoperative complications were compared at the end of 12 weeks between two groups. The ABG of $\leq 10 \mathrm{~dB}$ was achieved in $69 \%$ of cases in group A and $76 \%$ of cases in group B. There was a significant short-term (1 week) improvement in the Dizziness Handicap Inventory score $(p=00)$ with patients of adipose tissue seal compared to the gelfoam. Although the audiological outcomes were comparable between the two groups, the use of the adipose tissue can be a better alternative than gelfoam to control vertigo in the early postoperative period without causing any significant morbidity to the patient.
\end{abstract}

Keywords Endoscopic stapes surgery .

Adipose tissue seal · Gelfoam seal · Comparison

\section{Introduction}

Because of the enhanced visualization of the middle ear, endoscopic stapedotomy has become more popular in recent times. It ensures the preservation of the posterior canal wall along with the chorda tympani nerve in the

Pradeep Pradhan

padiapradhan@gmail.com

1 Department of ENT and Head Neck Surgery, All India Institute of Medical Sciences (AIIMS), Bhubaneswar, Odisha 751019, India majority of cases [1-3]. The improved visual field could have been possible due to the advancement of the rigid endoscopes for the inspection of the detailed middle ear structures far away from the surgical field $[4,5]$. Although satisfactory clinical and audiological results have been obtained in endoscopic stapes surgery as reported in the literature [6], the vestibular dysfunction (giddiness) in the postoperative period is rarely described. Various autologous and synthetic materials have been used in the past to seal the oval window to overcome the commonest complication, i.e., giddiness resulted in inconsistent control over vertigo in spite of similar hearing outcomes [7, 8]. Amongst all, gelfoam and fat are common sealing materials used for the closure of the stapes fenestra irrespective of the surgical techniques. Autologous fat, because of its better sealing properties, could be more effective in controlling postoperative vertigo besides significant improvement in hearing [8]. In the present study, we have compared the efficacy between the commonly used sealing materials, i.e., adipose tissue and the gelfoam, with concern to the audiological and vestibular outcome in the postoperative period in patients undergoing primary endoscopic stapes surgery.

\section{Materials and Methods}

This was a retrospective study of patients who were operated in the Department of Otorhinolaryngology between May 2017 and Feb 2019. A total of 58 patients of bilateral otosclerosis were included in the study, which was allocated into two groups (gelfoam and fat plugging groups, each containing 29 patients each) by quasi randomization i.e., alternatively designated into either group. All the patients underwent endoscopic stapedotomy with 
the help of a $3 \mathrm{~mm}$ nasal rigid endoscope. Gelfoam and lobular fat were used for plugging of the stapes window in group A and group B, respectively, containing 29 patients each. The diagnosis was made after the detailed clinical history, otoscopic features suggesting intact tympanic membrane, and conductive deafness of more than $20 \mathrm{~dB}$ HL with a normal bone conduction threshold (at the frequency of $500 \mathrm{~Hz}, 1 \mathrm{kHz}, 2 \mathrm{kHz}$, and $4 \mathrm{kHz}$ ) with the complete absence of the stapedial reflex. Patients presenting with mixed hearing loss were excluded from the study. The demographic and clinical profile of the patients, including the diameter of the auditory canal, pure tone audiogram (PTA), were noted in the preoperative period. Patients were counselled in the preoperative period regarding the surgical outcome and the expected postoperative complications attributed to the surgery. Written informed consent was taken for each patient before the surgery. All the patients were operated by a single surgeon under local anaesthesia. Xylocaine $2 \%$ with adrenaline was injected in the canal, covering all four quadrants. Transcanal incision was given $6 \mathrm{~mm}$ lateral to the annulus, from 6 o'clock to 12 o'clock position (Fig. 1). The meatal flap was elevated carefully until the middle ear cavity was reached. In selective cases, canaloplasty was performed, especially in a narrow/over hanged auditory canal. Again, the posterior canal wall was curetted in cases where there occurred incomplete visualization of the horizontal segment of the fallopian canal and the base of the pyramidal process (Fig. 2). After complete exposure of the mesotympanum, the otosclerotic focus was identified in each case. The stapedial tendon was incised with the help of a curved micro scissor. Both the anterior and posterior crus were fractured, and the suprastructure was removed with a forceps. Fenestra was made over the posterior half of the

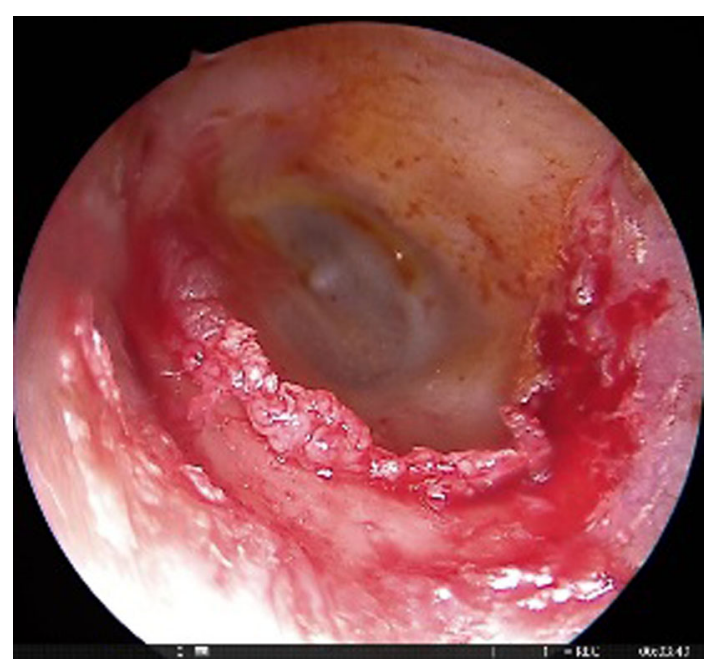

Fig. 1 Transcanal incision given (Right ear) from 6 o'clock to 12 o'clock poison

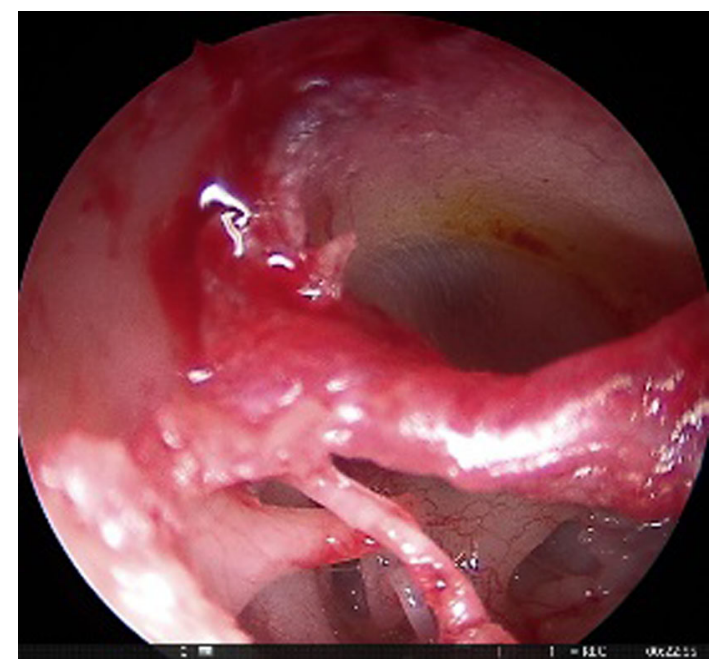

Fig. 2 Complete exposure of stapes suprastructure

footplate with perforator ( $0.8 \mathrm{~mm}$ diameter). Teflon piston (0.6 $\mathrm{mm}$ diameter) was inserted in all the cases after the measurement of the vertical height from the undersurface of the incus to the footplate (Fig. 3). In 29 patients, lobular fat was used for sealing of the stapes window, and in 29 patients, gelfoam was used (Fig. 4). The intraoperative hearing was assessed in each patient after complete insertion of the prosthesis. The auditory canal was packed with medicated gelfoam. The lobular incision was stitched, and a small dressing was placed over the pinna. Each patient was assessed for the intraoperative variables like the preservation of chorda tympani nerve, removal of the bony canal, operative time, and postoperative dizziness. Six hours after surgery, each patient was assessed for the presence of vertigo with or without of nystagmus.

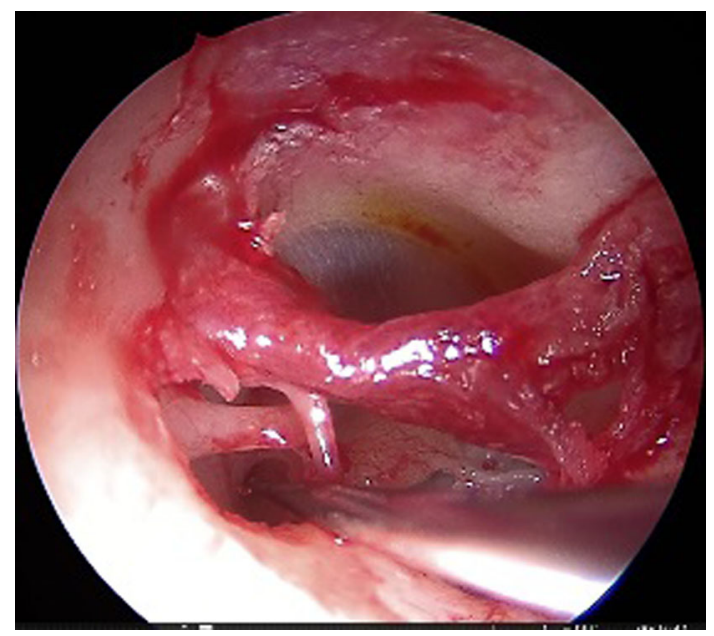

Fig. 3 Fenestra was made over the stapes footplate with $0.8 \mathrm{~mm}$ perforator 


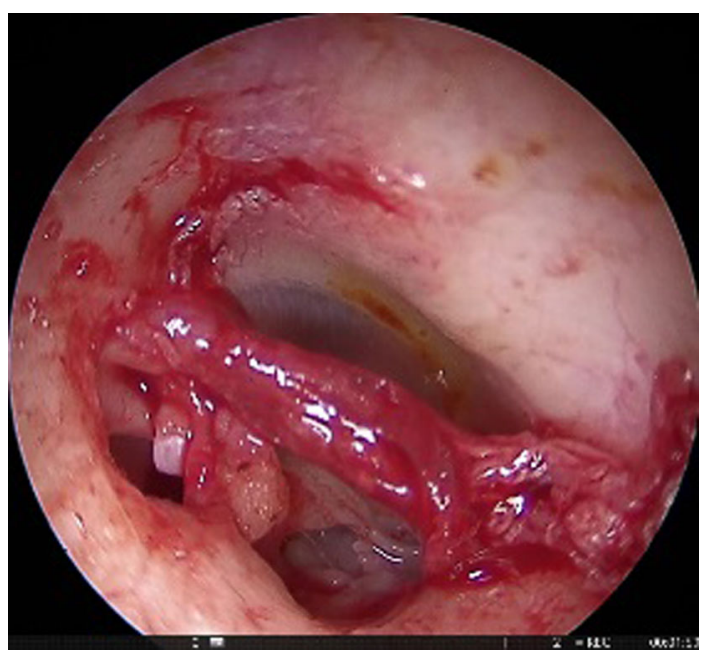

Fig. 4 Teflon piston ( $0.6 \mathrm{~mm}$ diameter, $4.25 \mathrm{~mm}$ length) was inserted through the stapedial window, anchored over the long process of incus, and a piece of lobular fat was used to seal the stapedial window after the insertion of the piston

\section{Follow-Up}

Patients were discharged $24 \mathrm{~h}$ after the surgery and advised to attend the otology clinic at 1,4 , and 12 weeks in the postoperative period. During each follow-up period, patients were subjected to otoscopic examination and PTA to assess the anatomical and audiological outcomes. At the end of 12 weeks, both the air conduction and the bone conduction thresholds were measured and later compared between the preoperative the postoperative audiogram and at the frequency of $500 \mathrm{~Hz}, 1 \mathrm{kHz}, 2 \mathrm{kHz}$, and $4 \mathrm{kHz}$ in both the groups. Similarly, the mean postoperative airbone gap $(\mathrm{ABG})$ was compared with the preoperative value. Giddiness was evaluated after 1, 4, and 12 weeks of surgery by using the dizziness handicap inventory (DHI) score and later was compared between the two groups. When the dizziness score was $<30$, later was considered insignificant without affecting the routine daily activities.

\section{Statistical Analysis}

Results were presented as n (\%), mean (range), standard deviation (SD), Standard error difference (SED), Confidence interval (CI). Preoperative and postoperative data were compared using the unpaired ' $t$ ' test, and Categorical variables between groups were analyzed using the Chisquared test or Fisher's exact test. Statistical package SPSS v 20.0 was used for the statistical analysis of the data.

\section{Results}

A total of 58 surgeries were performed for bilateral otosclerosis using a $3 \mathrm{~mm}$ otoendoscope. Adipose tissue and gelfoam were used in group A and group B, respectively, for oval window sealing. During the follow-up period, 3 patients in group A and 4 patients in group B were lost; hence total 26 patients in group A and 25 patients in group $\mathrm{B}$ were considered for the final analysis (Fig. 5). The mean age of the patients in group A was 35 years (range 22-48), and patients in group B was 30 years (range 19-45). Almost all (91\%) of patients in group A and in group B were females. The average period of follow-up for the group A patients was 8 months (range 5-17 months), and for group B, it was 5 months (3-11 months). The demographic data and intraoperative findings have been described in the Table 1 . The average duration of the surgery in group A was $42 \mathrm{~min}$ (range 29-65 min), and in group B, it was approximately $32 \mathrm{~min}$ (range 38-70 min). Chorda tympani nerve was found to be injured only in one patient in group B, and it was completely spared in patients with group A. Patients were first evaluated in the postoperative period 6 hours after the surgery. Otosclerotic foci were detected anterior to the oval window in almost all the cases in both the groups, except one patient in group B where the foot plate was found to be thick and obliterative. Stapedotomy was performed after adequate thinning out the footplate with the micro drill. A total $8(30.76 \%)$ patients in group A and 15 (60\%) patients in group B had presented with giddiness in the immediate postoperative period where the difference was found to be significant ( $p=0.03$ ). Similarly, spontaneous nystagmus was detected in 10 patients (4 in group A and 6 in group B) six hours after surgery $(p=0.04)$. The preoperative ABG in group A was $37.51 \pm 7.2 \mathrm{~dB}$, and in patients of group $\mathrm{B}$, it was $36.66 \pm 8.6 \mathrm{~dB}$. Postoperative ABG in patients of group A and group $\mathrm{B}$ was found to be $13.92 \pm 6.8 \mathrm{~dB}$ and $15.42 \pm 7.5 \mathrm{~dB}$, respectively. Similarly, the postoperative $\mathrm{AB}$-closure $(\mathrm{ABC})$ in group $\mathrm{A}$ and group $\mathrm{B}$ were $23.10 \pm 11.64 \mathrm{~dB}$ and $22.20 \pm 12.24 \mathrm{~dB}$, respectively (Table 2). There was a significant difference between the preoperative and postoperative $\mathrm{ABG}$ in each group $(p<0.05)$. Approximatly $70 \%$ patients in group $\mathrm{A}$ and $76 \%$ cases in group $\mathrm{B}$ had $\leq 10 \mathrm{~dB}$ ABG at the end of 12 weeks follow-up. Again, $92 \%$ of the patients in group A and group $B$ had $<20 \mathrm{~dB}$ closure of the $A B G$ in the postoperative period (Table 3). The mean DHI score at the end of one week was $43.92 \pm 6.63$ in group $A$ and $51.68 \pm 11.38$ in group B, respectively $(p=0.00)$ (Table 4). Similarly, the mean DHI score in group A was $22.38 \pm 9.33$, and in group, B was $18.64 \pm 6.67$ at the end of 4 weeks $(p=0.10)$ (Fig. 6). None of the patients in both 
Fig. 5 Study design

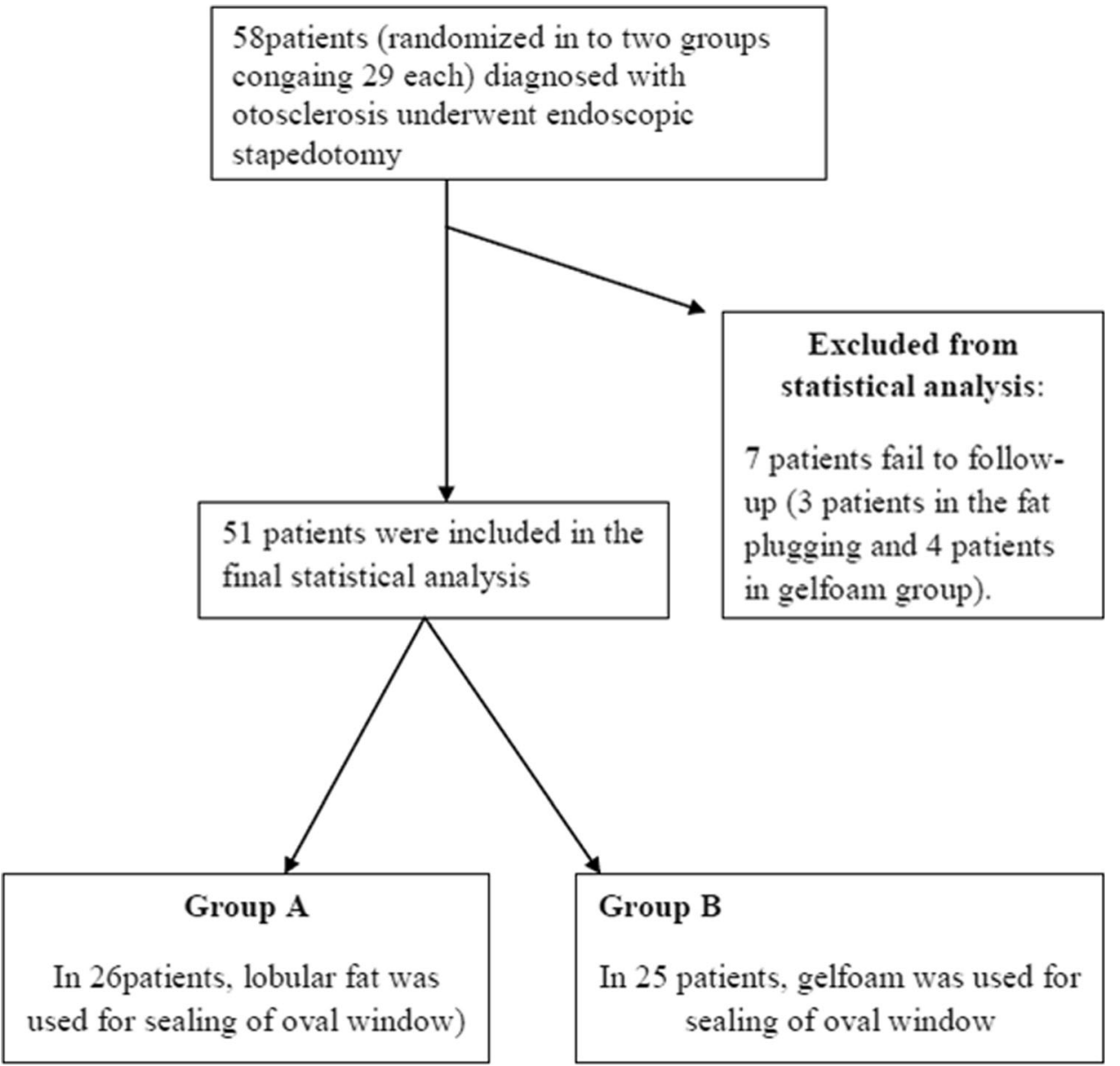

Table 1 Demographic data and patients characteristics of the study population $(n=46)$

\begin{tabular}{llll}
\hline & $\begin{array}{l}\text { Lobular fat } \\
(\mathrm{n}=26)\end{array}$ & $\begin{array}{l}\text { Gelfoam } \\
(\mathrm{n}=25)\end{array}$ & $\begin{array}{l}p \text { value } \\
\chi^{2} \text { test }\end{array}$ \\
\hline Number of procedures & 26 & 25 & 30 (range 19-45) \\
Age (years) & 35 (range 22-48) & $21(91 \%)$ & $19(71 \%)$ \\
Female (\%) & $20(91 \%)$ & $2(7.69 \%)$ \\
Ear, right (\%) & $15(68 \%)$ & $00(0.00 \%)$ \\
Canaloplasty & $01(3.84 \%)$ & $15(60 \%)$ \\
Chorda tympani nerve injury & $01(3.84 \%)$ & $6(24 \%)$ & $3(12 \%)$ \\
Giddiness (After 6 h) & $8(30.76 \%)$ & $01(4 \%)$ \\
Nystagmus (After 6 h) & $4(15.38 \%)$ & $00(\%)$ \\
Giddiness (After 1 week) & $2(7.69 \%)$ & 05 (range 3-11) \\
TM injury & $02(9 \%)$ & 32 (range 38-70) \\
TM perforation & $00(0 \%)$ & 2.72 (range2-4) \\
Follow-up (months) & $08($ range 5-17) & 0.33 \\
Operative time (minutes) & 42 (range 29-65) & 0.19 \\
Hospital stay (days) & 2.38 (range 2-4) & 0.27 \\
\hline
\end{tabular}

the group had sensorineural hearing loss (SNHL) till the last follow-up period. Again, when the mean DHI score was compared between the two groups at the end of
12 weeks, it was found to be insignificant $(p=0.30)$. One patient in the gelfoam group had floating footplate in during surgery, which was managed conservatively. The 
Table 2 Pre and postoperative hearing results for lobular fat and gelfoam groups

\begin{tabular}{llll}
\hline Characteristics & Lobular fat $(\mathrm{n}=26)$ & Gelfoam $(\mathrm{n}=25)$ & $p, 95 \%$ CI, SEM \\
\hline Sealing of foot plate & & & \\
Preoperative ABG & $37.51 \pm 7.2 \mathrm{~dB}$ & $36.66 \pm 8.6 \mathrm{~dB}$ & $p=0.70,(\mathrm{CI}-3.6-5.3)$, SEM $=2.2$ \\
Postoperative ABG & $13.92 \pm 6.8 \mathrm{~dB}$ & $15.42 \pm 7.5 \mathrm{~dB}$ & $p=0.56, \mathrm{CI}(-5.5-2.5)$, SEM $=2.0$ \\
ABC & $23.10 \pm 11.64 \mathrm{~dB}$ & $22.20 \pm 12.24 \mathrm{~dB}$ & $p=0.78, \mathrm{CI}(-5.8-7.6)$, SEM $=3.3$
\end{tabular}

$C I$; confidence interval, $d B$; decibel, $A B G$; air bone gap, $A B C$; Air bone closure, $S E M$; standard error mean

Table 3 Air-bone gap reported in bins of 10 decibels

\begin{tabular}{lllr}
\hline ABG $(\mathrm{dB}$ HL) & $\begin{array}{l}\text { Group A }(\mathrm{n}=26) \\
\text { Number of patients }(\%)\end{array}$ & $\begin{array}{l}\text { Group B }(\mathrm{n}=25) \\
\text { Number of patients }(\%)\end{array}$ & $\begin{array}{l}p \text { value } \\
\chi^{2} \text { test }\end{array}$ \\
\hline $0-10 \mathrm{~dB}$ & $18(69.23 \%)$ & $19(76.00 \%)$ & $p=0.82$ \\
$11-20 \mathrm{~dB}$ & $6(23.07 \%)$ & $4(16.00 \%)$ & $p=0.60$ \\
$21-30$ & $02(7.69 \%)$ & $02(8.00 \%)$ & $p=0.97$ \\
\hline
\end{tabular}

$d B H L$; Decibel hearing loss, $A B G$; Air bone gap

Table 4 Mean DHI scores in the follow-up periods

\begin{tabular}{llll}
\hline Characteristics & Lobular fat $(\mathrm{n}=26)$ & Gelfoam $(\mathrm{n}=26)$ & $p, 95 \%$ CI, SEM \\
\hline Mean DHI score (1 week) & $43.92 \pm 6.63$ & $51.68 \pm 11.38$ & $p=0.00$, CI $(-12.9-2.5)$, SEM $=2.5$ \\
Mean DHI score (1 month) & $22.38 \pm 9.33$ & $18.64 \pm 6.67$ & $p=0.10$, CI $(-8.1-8.3)$, SEM $=2.2$ \\
Mean DHI score (3 months) & $14.80 \pm 5.85$ & $15.54 \pm 6.10$ & $p=0.66$, CI $(-2.6-4.1)$, SEM $=1.6$ \\
\hline
\end{tabular}

DHI; Dizziness Handicap Inventory, $C I$; confidence interval, SEM; standard error mean

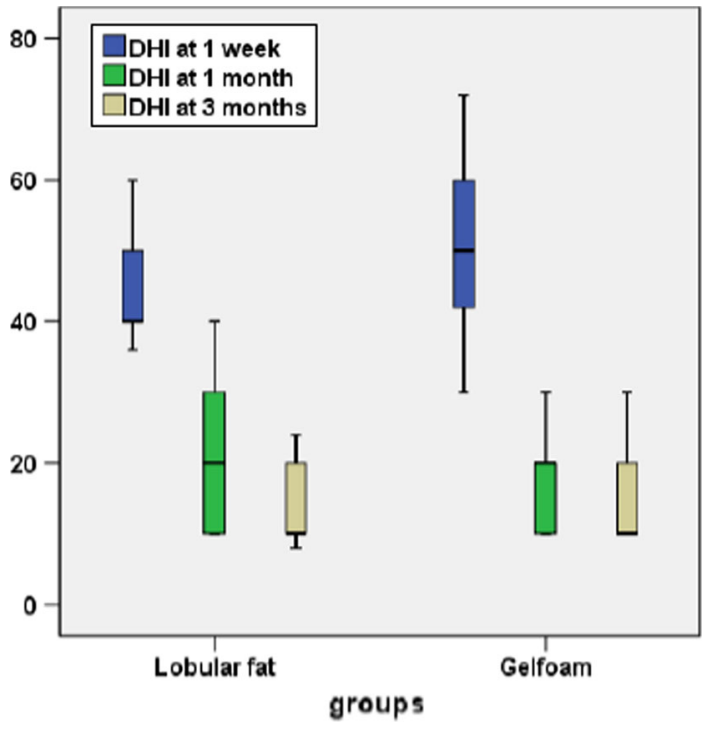

Fig. 6 Diagram shows the comparative DHI scores between fat and gelfoam plugging at the end of 1,4 and 12 weeks in the postoperative period tympanic membrane was injured in 2 patients in the fat sealing group and 4 patients in the gelfoam group during the elevation of the tympanomeatal flap, and none of the patients had any residual perforation till 12 weeks of follow-up. No other major complications were detected either in the intraoperative/postoperative period.

\section{Discussion}

In spite of the advancement in the endoscopic surgical techniques, the audiological outcomes and the postoperative complications with respect to the common tissue seals are not well documented in the world literature. In the present study, we have compared the effectiveness of the gelfoam and the adipose tissue in improving the audiological parameters and in controlling the postoperative giddiness in primary endoscopic stapes surgery. When the $\mathrm{AC}$ and $\mathrm{BC}$ thresholds were evaluated for both the groups in preoperative and postoperative periods, it had been 
found that there was a significant improvement in the $\mathrm{AC}$ threshold $(p=0.00)$, with significant closure of the ABG ( $p=0.00)$ in both the groups. But on comparing the $\mathrm{AC}$ and $\mathrm{ABG}$, we did not find any significant difference between them $(p>0.05)$. Again, $69 \%$ of the patients in group A and $76 \%$ of patients in group B had $<10 \mathrm{~dB}$ of $\mathrm{ABG}$ and approximately $80 \%$ of the patients in both groups had $<15 \mathrm{~dB}$ of $\mathrm{ABG}$ at the end of 12 weeks in the postoperative period. Similar results were obtained in a study conducted by Faramarzi et al. [9] showing similar $\mathrm{ABG}$ in both the fat and gelfoam group $(p>0.05)$. Gelfoam was considered to be ototoxic due to the presence of the formaldehyde used during the sterilization process [10], which has been significantly minimized after the modification in the sterilization, reducing the harmful effect of the later [11]. As described by Shenoi, 20-60 $\mu \mathrm{g}$ of formaldehyde can be harmful to the organ of Corti, and the chance of sensorineural hearing loss will be more with an increment of the sterilizing agent. Meltzer et al. compared vein plug or fat plug with Gelfoam in stapedectomy. They achieved $\mathrm{ABG}$ within $10 \mathrm{~dB}$ in $71 \%$ of the patients, in the vein or fat plug group and $75 \%$ in the Gelfoam group [12]. Successful hearing outcomes have also been reported in the previous studies using the fat and gelfoam as sealing material in stapes surgery $[13,14]$. In contrast, in the present study, we did not find any patient in the gelfoam group with sensorineural hearing loss till 3 months of follow-ups in any of the groups. Vertigo in the early postoperative period is the commonest morbidity in the postoperative period attributed to the stapes surgery [15-18]. Although the cause of postoperative giddiness is thought to be multifactorial, the loss of perilymph could be the major contributor attributed to this. Various autologous tissue and synthetic materials have been used for sealing of the stapes window to minimize postoperative vertigo, although gelfoam and adipose tissue being the commonest among them. In the present study, $8(30.76 \%)$ patients in the adipose tissue group and $15(60 \%)$ in the gelfoam group had unsteadiness in the immediate postoperative period ( $p=0.03$ ), who required vestibular sedative. But spontaneous nystagmus was detected in 4 patients in the adipose group and 6 patients in the gelfoam group $(p=0.04)$. Again when the DHI scores were compared between the two groups at the end of 1 week, it was evident that the patients with the adipose tissue group had a significantly lower giddiness score than that of the gelfoam group $(p=00)$. At 4 weeks and 12 weeks of surgery, on comparison of the DHI scores between the two groups, we did not find any significant difference between them $(p>0.05)$. This short term control in vertigo could have been due to the optimized sealing of the stapes window with the adipose tissue, minimizing loss of perilymph. Giddiness in stapes surgery can be seen early [7] in the postoperative period, or it can be encountered in the delayed postoperative period [19], later can delay the hospital stay. As demonstrated in the present study, when the DHI scores were evaluated between the two groups, most of the patients in both the groups became free of vertigo after one week of surgery, but the patients with the fat sealing group had a better vertigo control rate compared to the gelfoam. With respect to the hospital stay, we did not find any significant difference between the two groups, although the mean operative period was longer in the adipose group. Again none of the patients in any the group had sensorineural hearing loss (SNHL) till the 12 weeks of the follow-up period in contrast to the published literature [20]. The tympanic membrane was injured in 2 patients in the fat sealing group and 4 patients in the gelfoam group during the elevation of the tympanomeatal flap, and none of the patients had any residual perforation till 12 weeks of follow-up. According to McNeil, untraumatized adipose tissue and fat can provide an adequate inner barrier for the protection of the inner ear [6]. However, others have claimed that gelfoam produces a thinner membrane than the tissue graft [21, 22]. Although the incidence of perilymph fistula is found to be $0.9 \%$ in stapedectomies, it was negligible in stapedotomies surgeries [23] as obtained in the present study. Adipose tissue can be considered a better autograft compared to the gelfoam for sealing of the stapes widow in primary endoscopic stapedotomy, ensuring adequate control of vertigo in the early postoperative period besides significant improvement in the hearing outcome. A large sample size with a long term follow-up may be required for a better understanding of the results.

\section{Conclusion}

Adipose tissue and gelfoam are the commonly used sealing materials in primary endoscopic stapes surgery. Although they have a comparable hearing outcome, the vertigo control in the early postoperative period was significantly better in patients with adipose tissue seal. A large sample size with a long term follow-up may be required for a better understanding of the results.

Acknowledgements The author would like to acknowledge that the study was conducted in All India Institute of Medical Sciences, Bhubaneswar, in the Department of ENT and Head Neck Surgery. There are no conflicts of interest among the authors. This research has not been supported by any financial agency or funding organization. 
Funding The study was funded by aiims, Bhubaneswar, in the form of an intramural funded grant.

\section{Compliance with Ethical Standards}

Conflict of interest There are no conflicts of interest among the authors.

Human and Animal Rights All procedures performed in studies involving human participants were in accordance with the ethical standards of the institutional and/or national research committee and with the 1964 Helsinki declaration and its later amendments or comparable ethical standards.

Informed Consent Institutional ethical committee approval has been taken for the research. Written informed consent has been taken from each patient prior to the surgery and same has been informed to the institute reviewer board. No part of the body has been demonstrated in the case report without the permission of the concerned patient.

Open Access This article is licensed under a Creative Commons Attribution 4.0 International License, which permits use, sharing, adaptation, distribution and reproduction in any medium or format, as long as you give appropriate credit to the original author(s) and the source, provide a link to the Creative Commons licence, and indicate if changes were made. The images or other third party material in this article are included in the article's Creative Commons licence, unless indicated otherwise in a credit line to the material. If material is not included in the article's Creative Commons licence and your intended use is not permitted by statutory regulation or exceeds the permitted use, you will need to obtain permission directly from the copyright holder. To view a copy of this licence, visit http://creativecommons. org/licenses/by/4.0/.

\section{References}

1. Hunter JB, Rivas A (2016) Outcomes following endoscopic stapes surgery. Otolaryngol Clin North Am 49:1215-1225

2. Kojima H, Komori M, Chikazawa S et al (2014) Comparison between endoscopic and microscopic stapes surgery. Laryngoscope 124:266-271

3. Iannella G, Marcotullio D, Re M et al (2017) Endoscopic vs microscopic approach in stapes surgery: advantages in the middle ear structures visualization and trainee's point of view. J Int Adv Otol 13:14-20

4. Tarabichi M (1999) Endoscopic middle ear surgery. Ann Otol Rhinol Laryngol 108:39-46

5. Bottrill ID, Poe DS (1995) Endoscope-assisted ear surgery. Am J Otol 16:158-163

6. Raut VV, Toner JG, Kerr AG, Stevenson M (2002) Management of otosclerosis in the UK. Clin Otolaryngol Allied Sci 27(2):113-119

7. Lin KF, Selesnick S (2016) Stapedotomy with adipose tissue seal: hearing outcomes, incidence of sensorineural hearing loss, and comparison to alternative techniques. Otol Neurotol 37(7):851-858

8. Nassiri AM, Yawn RJ, Dedmon MM, Tolisano AM, Hunter JB, Isaacson B, Rivas A (2018) Otol Neurotol. 39(9):1095-1101

9. Faramarzi M, Roosta S, Aminpour S (2019) Comparinggelfoamvsfatasasealingmaterialinstapedotomy: a prospective double-blind randomised clinical trial. Clin Otolaryngol 44(3):299-304

10. Incesulu A, Hausler R (2007) Advantages and risks of various sealing procedures of the oval window: vein graft, adipose tissue, gelfoam, merogel. Adv Otorhinolaryngol 65:206-209

11. Shenoi PM (1973) Ototoxicity of absorbable gelatin sponge. Proc R Soc Med 66(2):193-196

12. Meltzer P, Cawthorne T, Derlacki E et al (1963) Panel on techniques and results of stapes surgery. Arch Otolaryngol 78:546-573

13. Testa J, Millas I, De Vuono IM, Neto M, Lobato M (2002) Otosclerose: resultados de estapedotomias. RevistaBrasileira deOtorrinolaringologia. 68:251-253

14. Surmelioglu O, Ozdemir S, Tarkan O, Tuncer U, Dagkiran M, Cetik F (2016) Endoscopic versus microscopic stapes surgery. Auris Nasus Larynx 44(3):253-257

15. Aantaa E, Virolainen E (1978) The pre- and postoperative ENGfindings in clinical otosclerosis and the late hearing results. Acta Otolaryngol 85:313-317

16. Kujala J, Aalto H, Hirvonen TP (2005) Video-oculography findings in patients with otosclerosis. Otol Neurotol 26:1134-1137

17. Birch L, Elbrond O (1985) Stapedectomy and vertigo. Clin Otolaryngol 10:217-223

18. Silverstein H, Rosenberg S, Jones R (1989) Small fenestra stapedotomies with and without KTP laser: a comparison. Laryngoscope 99:484-488

19. Vasama JP, Kujala J, Hirvonen TP (2006) Is small-fenestra stapedotomy a safer outpatient procedure than total spapedectomy? ORL J Otolaryngol Relat Spec 68:99-102

20. Vincent R, Sperling NM, Oates J, Jindal M (2006) Surgical findings and long-term hearing results in 3,050 stapedotomies for primary otosclerosis: a prospective study with the otology-neurotology database. Otol Neurotol 27:S25-247

21. Goldman JL, Morgenstein KM, Druss JG, Nalebuff DJ, Rosen S (1963) Experimental observations on prostheses and oval window coverings in cats as related to stapedial surgery. Laryngoscope 73:868-892

22. McNeill RA (1968) The protective properties of fat and gelfoam as oval window grafts. J Laryngol Otol 82(1):17-22

23. Somers T, Govaerts P, Marquet T, Offeciers E (1994) Statistical analysis of otosclerosis surgery performed by Jean Marquet. Ann Otol Rhinol Laryngol 103(12):945

Publisher's Note Springer Nature remains neutral with regard to jurisdictional claims in published maps and institutional affiliations. 